\section{A New Tide Gauge}

AT a meeting of the Royal Society held on March 22, 1838, Mr. T. G. Bunt gave a description of a new tide gauge constructed by himself, and erected on the eastern bank of the River Avon, in front of the Hotwells House, Bristol. In this apparatus a float was connected by a wire to a wheel and drum, $1 / 18$ of the vertical motion of the float being given to a bar carrying a pencil which recorded the rise and fall of the water on a paper on a cylinder driven by an eight-day clock.

\section{Dublin Zoological Society}

"THIs institution," said the Mechanics' Magazine of March 24, 1838, "has in some degree overcome the difficulties whose occurrence seemed to threaten its very existence a short time ago. Extraordinary means, however, are obliged to be resorted to, in order to make up the deficiency of funds under which it labours. Among these is a series of lectures on Natural History delivered gratuitously by some of the most eminent physicians of the Irish capital, under the patronage of the Lord Lieutenant. It would be a pity indeed, if 'the second city in the Empire' should, like too many of our large provincial towns, suffer its Zoological Gardens to fall into decay after a short season of flattering success."

\section{New Professorships in Paris}

THE Athenceum of March 24, 1838, stated that "Dr. Duvernoy, of Strasbourg, at which place he holds a high situation in the university, has been appointed to the new professorship at the Collège de France, named the 'Natural History of Organised Bodies'. M. Poncelet, of the Academy of Sciences, has also been elected to the new chair of Physical and Experimental Mechanics, belonging to the Faculty of Sciences, and which has been created in consequence of the increasing manufactures and industry in France. A third chair has been instituted at the Jardin des Plantes, viz., that of Comparative Physiology, which has been given to the Chevalier Cuvier. To this list may be added the election of M. Audouin, the entomologist to the Academy of Sciences".

\section{James Lowe's Screw Propeller}

Two years after John Ericsson and Francis Pettit Smith patented their screw propellers, James Lowe (1798-1866) took out patent No. 7599 of March 24, 1838 for improvements in propelling vessels "by means of one or more curved blades set or fixed on a revolving shaft below the water line of the vessel". His propeller was tried in H.M.S. Wizard and afterwards in H.M.S. Rattler and H.M.S. Phœnix. In 1844 he brought an action against Penns of Greenwich for infringement, and the evidence showed that although Lowe was not the original inventor of screw propellers he was the first to use the combination of a segment of a screw, and of a segment applied to an axis below the water and with the segment totally submersed. Lowe, who was born May 13, 1798, was an apprentice of Edward Shorter, the London inventor of "the perpetual sculling machine", and became a merchant and smoke jack maker. He met his death by being run over by a wagon on October 12, 1866. $\mathrm{He}$ is buried in the churchyard at Ewell, Surrey.

\section{Societies and Academies Dublin}

Royal Irish Academy, January 24.

B. N. Singh : Cytoplasmic bodies in the oogenesis of the vulture (Neophron percnopterus ginginianus), with special reference to the effect of ultra-centrifuging on the oocytes of the pigeon. After ultra-centrifuging, the cytoplasmic bodies in the oocytes of the pigeon are stratified as follows : fat and cholesterol at the centripetal end; next, a layer of Golgi bodies, followed by a layer of mitochondrial yolk, and the mitochondria which are the heaviest components in the cell and occupy the extreme centrifugal end. No relationship exists between sudanophil fat and the Golgi bodies. Cholesterol bodies filter in from the egg membranes to the oocytes in the pigeon. No pre-existing 'vacuome' could be seen.

R. W. DitchвuRN : Diffraction by irregular gratings. The properties of gratings in which the spaces between the lines and the intensity scattered by a given line are not constants are discussed. It is shown that general expressions of a fairly simple type can be given for the diffraction functions but that it is difficult to apply these general expressions in the design of gratings. By computation and trial and error it is, however, possible to design gratings which have interesting and useful properties. In par. ticular, it is possible to increase the resolving power considerably by the omission of some of the rulings of an ordinary grating. Examples of the application of the theory to line and echelon gratings are given.

Archre Lamont : Contemporaneous slumping and other problems at Bray Series, Ordovician, and Lower Carboniferous horizons in County Dublin. Accounts are given of submarine sliding of sediments. These appear to have been a surface expression of deep-seated tectonic adjustments. The Ordovician slumping corresponds with a horizon close to the transition between Caradocian and Ashgillian, and evidence of movement of a fault at this juncture is adduced. Carboniferous landslides, apparently set off by seismic agencies, were intensified during the Nassauian and Sudetic phases of mountain-building on the Continent. Anti-dune structures produced by anomalous marine currents are described.

J. SELWYN TURNER contributes a revision of the Carboniferous stratigraphy of the district.

\section{Paris}

Academy of Sciences, January 17 (C.R., 206, 137-220).

EMILE BoREL : The laws of the probable evolution of finite ensembles of segments.

Henri Colin: Affinity and specific chemism in grafted Helianthus.

GaBriel Bertrand : An unexpected intervention of the manure industry in reducing the fertility of soils. It has been shown that boron is an essential element for certain crops. Potash from Alsace contains boron, but the purification of the crude sylvinite, while raising the percentage of potassium substantially, reduces the proportion of boron, with a possibly prejudicial effect on the crops.

François Grandjean: The ontogeny of the Acarians.

Hyacinthe Vincent : Experimental typhoid in. fection by the method of protected inoculations.

Gustave MaLÉcot: The analysis of chances and the problem of heredity.

H. ADAD : Circles paratactic to two given circles and surfaces several times encircled. 
André Lrchnerowicz: The singularities of the exterior $d s^{2}$

Gustave Choquet : Study of plane homeomorphies.

RENÉ HIRsch : The stabilization of aeroplanes.

LÉOPOLD Escande: Flow through a submerged valve gate.

Henri Mineur: The dynamical equilibrium of galactic clouds.

Junior GaUziT : The spectrum of the Finsler comet in the visible region. Outline of results obtained at the Lyons Observatory, with a criticism of the conclusions drawn by $R$. Minkowski regarding the presence of the red spectrum of cyanogen in the Finsler comet.

JEAN XaNTHAKIS: The variation of azimuth of the line of the meridional sights of the Strasbourg Observatory.

Louis Routin : An improvement in the applications of the gramophone to teaching.

Furle PierRet : The electronic oscillations of triode valves. Experiments showing that triode valves with unsupported spiral grid can give rise to electronic oscillations of well-defined frequency.

Charles Haenny: Photographs of multiple rays in the subsoil.

Maurice Rey, Henri Herbiet and Pierre CoHEUR : The influence of cobalt salts on the anodic behaviour of lead in a sulphated electrolyte.

Mlle. Yvette Cauchols and Horia Huluber : Non-characteristic white and dark lines in the spectra of X-rays obtained by crystalline diffraction.

Roger Arnoult : The continuous $\beta$-spectrum of thorium-B.

Marie Louise Delwaulle, Félix François and Joseph WiEmanN : The application of the Raman effect to the study of the constitution of solutions of zinc iodide and cadmium iodide.

P. Brllair : The origin of the Pelvoux granite. ANDRE WAHI, Martinus GoEdKoOP and EDOUARD HeBerLerN : $\alpha$ - and $\beta$-naphthoylacetic esters.

ARNOLD BERSIER: The character and meaning of the sedimentation in the alpine pre-fosse (external phase).

Marius Dalloni : Intrusion of the Cenomanian on the primary axial zone of the Ariegeois Pyrenees.

Georges Choubert : The Dogger of the eastern Haut-Atlas.

ANDRÉ MEYENDORFF : The primary series of Gourara.

Grirald Andrew and Jean Cuviluier : The discovery of the marine Oligocene in the region of Borg el-Arab.

Pierre Dangeard: A new Cystoseira from the Cap Vert Peninsula, C. senegalensis, and on some other African Cystoseira.

Jean Fleckinger: The size of the flowers and pilosity of the calyx in relation to polyploidy in the apple tree.

Léon Acolat : Comparative study of the blood pressure in the pulmonary circuit and in the general circuit in Batrachians and reptiles.

A. JuLlien and D. VINCENT: The action of acetylcholine on the heart of molluscs. The curareacetylcholine antagonism.

HenRy Schwas : The opposed effect of small and large doses of aluminium salts in hypoglycæmia due to insulin and hyperglycæmia due to adrenalin.

Gabriet Florence and Mme. Andrée Drinhon : The absorption in theultra-violet of blood ultra-filtrate.

Emrla Rousseau : Differential reaction between blood or urine of cancerous and normal subjects.
Micher Flanzy and Marcer Banos: The presence of secondary propyl alcohol in alcohol from wine. Secondary propyl alcohol appears to be a normal constituent of alcohol from wine.

\section{Moscow}

Academy of Sciences (C.R., 17, No. 6, 1937).

S. Bernstein : Some modifications of the inequality of Tchebysheff.

M. KRAVČUK : Some approximations in the problem of moments for the functions with two variables.

B. ILEWrtan : (1) A new generalization of quasiperiodic functions. (2) Linear differential equations with quasi-periodic coefficients.

N. Котсніл: A particular case of Riemann's problem.

I. VÉCOUA : General representation of solutions of equations with partial derivatives of the second order.

N. Moisserev: Problem of the localization of dynamic trajectories in the space of phases.

L. LANDAU: Origin of stellar energy.

N. Wassmuth : Contributions to the theory of Brownian movement.

G. L. ShNIRMan : An elementary theory of the spring suspension of the vertical seismograph.

M. K. Tiknonov : Corrosion of iron at the boundary : metal-liquid-gas and metal-liquid-liquid.

N. A. Dziuban : Nutrition of some Cyclopidæ (Crustacea).

I. A. Filippenko, E. H. Gerber and O. $\mathrm{K}$. Elpidina : Photosynthesis as applied to citrous plants in natural conditions.

I. A. Filippenko: Formation of bios in the vernalized embryos of winter wheat.

$$
\text { C.R., 17, No. 7, } 1937 .
$$

N. Cudakov: Problem of Goldbach.

W. LiUkshin : Bending of rotation surfaces with negative curvature and a single point.

I. PetrovskiJ : Systems of differential equations all solutions of which are analytical.

J. G. Metschwarischwili : Limit solutions of differential equations of hyperbolic type with variable coefficients, in the case of two independent variables.

W. W. SHoulejkIN : Theory of monsoons. (3) The importance of the size and shape of continents and seas.

A. E. OstrovskiJ : Measurements of the rate of propagation of elastic vibrations on small bases.

N. N. Vorožcov, A. P. Alexandrov and T. I. Berkova : A new product of reaction between anthraquinone and alkali.

E. V. ZmačnnskiJ and L. I. Mališevskaja : New method for obtaining benzil from benzoin.

M. M. KaCnELson and M. S. Kondakova : Investigations on normal acids with a long chain, which is closed by a cyclohexyl or a cyclopentyl.

L. L. Ivanov: A chemico-microscopic study of a meteorite from the Yurtuk village, Dnepropetrovsk region, which fell on April 2, 1936.

I. SEDLECKIJ : Genesis of minerals from soil colloids of the group of montmorilonite.

N. A. ILJIN : Parallel variability in phenogenesis of the ear shell in Canidae.

O. G. Alexandrova: Anatomy of various types of wheat grain.

V. G. Amexandrov : Morphology of the grain of cereals.

A. A. VoITKEvič : Morphogenetic activity of different parts of the hypophysis. (9) On the gonadotropic action of the substance from the "basophile zone" of the anterior lobes of the hypophysis. 